\title{
A rare cause of insidious shoulder pain in a young female: A soft tissue aneurysmal bone cyst in supraspinatus muscle
}

\author{
Sibel Süzen Özbayrak @, Duygu Geler Külcü @ \\ Department of Physical Medicine and Rehabilitation, Health Sciences University, Haydarpaşa Numune Training and Research Hospital, Istanbul, Turkey
}

Received: August 16, 2019 Accepted: February 04, 2020 Published online: December 01, 2021

\begin{abstract}
Aneurysmal bone cyst $(\mathrm{ABC})$ is an expansile cystic lesion which may affect any bone of the skeleton. Although extremely rare, lesions with histomorphological characteristics of an $\mathrm{ABC}$ occur in the soft tissue. Herein, we report the first case of ABC involving the supraspinatus muscle and mimicking common pathologies, such as myofascial pain syndrome or subacromial impingement syndrome.

Keywords: Aneurysmal bone cyst, shoulder pain, soft tissue.
\end{abstract}

Aneurysmal bone cyst (ABC) is an expansile cystic lesion of numerous blood-filled channels which may affect any bone of the skeleton. It was first described by Jaffe and Lichtenstein ${ }^{[1]}$ in 1942. In 1972, Salm and Sissons ${ }^{[2]}$ defined soft tissue lesions resembling $\mathrm{ABCs}$, and it was probably the first description of this pathology. Soft tissue ABC is a rare entity, with about 20 cases reported in the literature until now. ${ }^{[3]}$ Few cases have been reported in the literature presenting with shoulder pain. Herein, we report the first case of $A B C$ presenting with shoulder pain and involving the supraspinatus muscle and discuss its clinical features and imaging findings in a young female.

\section{CASE REPORT}

A 21-year-old female patient was admitted to our clinic with an insidious shoulder pain, which was not related to activity for one year. Her medical history revealed no trauma or repeated shoulder movement causing damage to rotator cuff tendons. Physical examination findings were normal, except for mild tenderness in the supraspinatus tendon. Laboratory tests and direct X-ray results were unremarkable. Magnetic resonance imaging (MRI) of the shoulder was planned, as the symptoms persisted after one week of conservative treatment. The MRI revealed multiple cystic lesions with the fluid liquid level of approximately 4 to $5 \mathrm{~cm}$ in diameter in the supraspinatus muscle, posterior to the coracoid process, primarily considered as an $\mathrm{ABC}$. Contrast enhancement in the periosteum and mass in soft tissue were observed, suggesting an inflammatory reaction (Figures 1 and 2). The patient was referred to orthopedics and traumatology outpatient clinic. Shoulder computed tomography (CT) was taken for detailed evaluation of the bone involvement and destruction of the spine scapula by an expansive tumor mass was detected (Figure 3). Complete resection was planned and a written informed consent was obtained from the patient.

Complete resection of the mass was performed. Histomorphology of the excised material showed fibroblastic proliferation, osteoclast type giant cells with osteoblastic rim isolated from soft tissue with more

Corresponding author: Sibel Süzen Özbayrak, MD. SBÜ, Haydarpaşa Numune Ë̆itim ve Araştırma Hastanesi, Fiziksel Tip ve Rehabilitasyon Kliniği, 34668 Üsküdar, İstanbul, Türkiye. e-mail: sibels62@yahoo.com 


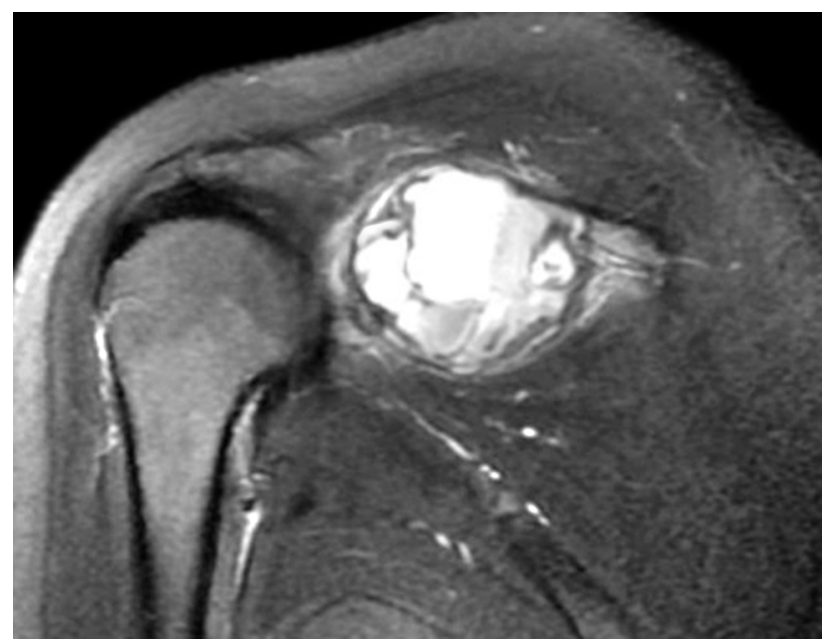

Figure 1. The coronal section of magnetic resonance imaging showing multiple cystic lesions.

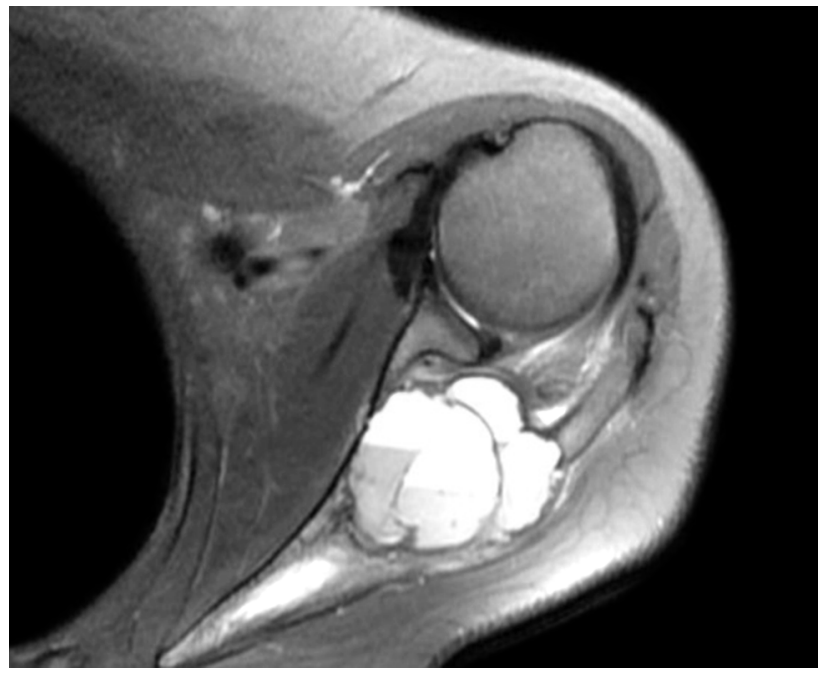

Figure 2. The axial section of magnetic resonance imaging showing multiple cystic lesions.

mature bone tissue areas, compatible with an $\mathrm{ABC}$. Four months after surgery, the range of motion of the shoulder was not limited in all directions. However, she was complaining of mild weakness during prolonged activity. The rehabilitation program consisting of strengthening exercises, electrical stimulation of periscapular muscles and transcutaneous electrical nerve stimulation (TENS) was applied for five a week for a total of four weeks. The patient is still under follow-up for possible tumor mass recurrence.

\section{DISCUSSION}

Aneurysmal bone cyst is a benign, blood-filled lesion in the bone which tends to expand or grow.

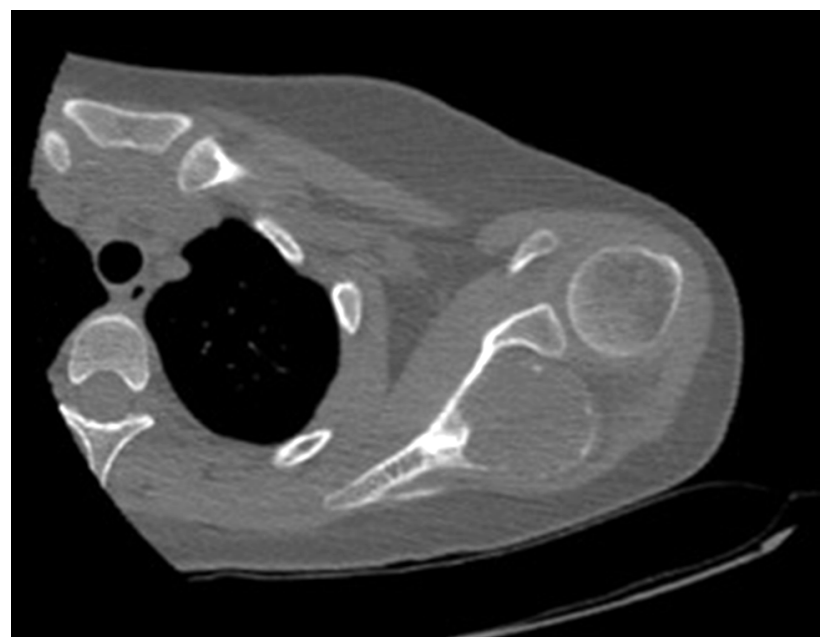

Figure 3. Computed tomography of shoulder showing destruction of spine scapula by an expansive tumor mass.

It most often affects individuals in their second decade of life as in the presented case with a median age of 13 years, and $90 \%$ of lesions are detected before 30 years of age. ${ }^{[4]}$ Females are slightly more affected with an estimated male-to-female sex ratio of 1:1.16. ${ }^{[4]}$ Few cases of soft tissue ABC were reported in the literature in the upper arm, including triceps muscle, retroclavicular and infraspinous region..$^{[5,6]}$ However, supraspinatus muscle involvement has not been described in the literature, yet. To the best of our knowledge, this is the first case of $\mathrm{ABC}$ involving the supraspinatus muscle.

Initially an $\mathrm{ABC}$ was thought to be a nonneoplastic condition, but recently, reproducible clonal chromosomal abnormalities have been described in both osseous and extraosseous $\mathrm{ABCs}$, suggesting a probable neoplastic nature. ${ }^{[7-9]}$ These cysts are typically solitary and are, currently, thought to arise either as primary neoplasms or secondary lesions adjacent to osteoblastomas, chondroblastomas or giant cell tumors. ${ }^{[10,11]}$

Although benign, ABCs can be locally aggressive. Their expansile nature can cause pain, swelling, deformity, disruption of growth plates or joint surfaces, neurological symptoms (depending on location), and pathological fractures. In our case, there was a mild shoulder pain, independent from the movement. On her physical examination there was tenderness on the supraspinatus muscle, mimicking myofascial pain syndrome. Robinson et al. ${ }^{[12]}$ compared a series of seven patients in whom a neoplasm was the underlying cause for the stiff shoulder with a series of 50 patients with primary or secondary frozen shoulder. In addition 
to a detailed history taking, physical examination, radiography, ultrasonography, and bone scanning were performed in all cases. The authors concluded that the most useful diagnostic test appeared to be a discrete area of bony tenderness, which was present in all seven patients with a tumor and in only five of 50 patients in the control group.

The diagnosis of $\mathrm{ABCs}$ is made based on various imaging modalities, exhibiting typical features such as fluid-fluid levels, although biopsy is critical, as telangiectatic osteosarcoma cannot be excluded based on imaging studies alone. ${ }^{[13]}$ Neither the cause of rotator cuff syndrome or supraspinatus tendinitis was present in our patient, nor did they present physical examination findings compatible with these diagnoses. Therefore and, considering the age of the patient, we did not prefer the treatment methods we frequently apply in shoulder problems such as trigger point injection, intra-articular injection, subacromial injection, or physical therapy.

Histologically, ABCs (both osseous and soft tissue) are comprised of blood-filled cysts with fibrous septa, which also contain giant cells, reactive woven bone, and fibroblasts. The hemorrhagic cystic spaces with peripheral woven bone are what cause $\mathrm{ABCs}$ (both soft tissue and osseous) to have their well-defined, expansile, lytic appearance with peripheral calcification on radiographs and $C T \cdot{ }^{[5,14,15]}$

Differential diagnosis for soft tissue ABCs includes myositis ossificans, nodular fasciitis with osteoclasttype giant cells, ossifying fibromyxoid tumor of the soft parts, calcified hematoma, extra-skeletal telangiectatic osteosarcoma, and giant cell tumor of soft tissue. A combination of clinical history, imaging characteristics, and pathological examination can allow differentiation of each entity. ${ }^{[3]}$

The typical peripheral calcification of soft tissue ABCs is not seen in nodular fasciitis and, thus, the entities should be readily differentiated by radiological-pathological correlation. On CT, nodular fasciitis lesions appear to be non-specific soft tissue masses, and MRI appearances are variable depending on the cellularity of the lesion. ${ }^{[16]}$

An ossifying fibromyxoid tumor may also feature peripheral woven/lamellar bone such as soft tissue ABCs, but in a more lobular and aggressive pattern on radiographs/CT, as opposed to the characteristically smoother margins of soft tissue ABCs. Ossifying fibromyxoid tumors featuring blood filled cystic spaces and fluid-fluid levels on MRI have not been reported, so far. ${ }^{[17]}$
Radiologically, giant cell tumors of soft tissue do not tend to have a calcified rim, such as soft tissue ABCs. Giant cell tumors of the soft tissue can rarely feature cystic change, necrosis, and/or hemorrhage with formation of fluid-fluid levels, although not usually to the extent of a soft tissue ABC. On histopathology, soft tissue $\mathrm{ABC}$ usually contain more reactive osteoid and woven bones, but fewer giant cells than a giant cell tumor of soft tissue or giant cell tumor of the tendon sheath. ${ }^{[18]}$

Clinical history often yields an antecedent history of trauma for myositis ossificans. The typical fluid-fluid levels and septated "honeycomb" enhancement pattern of soft tissue ABCs should not be seen. ${ }^{[19]}$

On radiography and CT, extra-skeletal telangiectatic osteosarcoma will typically feature a wider zone of transition and more aggressive and invasive behavior as a result of its malignancy. On MRI, an extra-skeletal telangiectatic osteosarcoma usually features fluid-fluid levels, but tends to have more nodularity and soft tissue components, as opposed to the septated "honeycomb" appearance of soft tissue ABCs. ${ }^{[20]}$

Treatment of ABCs is highly challenging, due to their locally aggressive nature and high rates of recurrence. Complete resection has the lowest rates of recurrence, but at the cost of high morbidity to the patient. ${ }^{[21]}$ Despite best efforts at curettage, clinical series have shown highly variable recurrence rates, with some series showing rates as high as $59 \% .{ }^{[22]}$ As a result, various adjuvants have evolved to reduce recurrence including the use of cement, high-speed burr, argon beam, phenol, and cryotherapy. ${ }^{[22]}$ Although radiation is most notably utilized in the treatment of malignancies, radiotherapy has historically been used to treat ABCs primarily, as an adjuvant therapy in cases of recurrence and in inoperable ABC lesions. ${ }^{[23]}$ Currently, the treatment strategy of choice relies largely on the approach and experience of the treating physician: minimize risk at the cost of increased recurrence and potentially repetitive treatment or accept risks with a more invasive, definitive procedure to reduce recurrence. ${ }^{[21]}$ Complete resection of the mass was performed in our case and, after operation, a rehabilitation program consisting of strengthening exercises, electrical stimulation of periscapular muscles, and TENS was applied for five days per week over four weeks. She is still under follow-up for possible tumor mass recurrence. 
In conclusion, soft tissue ABCs can occur in any age group and typically appear as peripherally calcified soft tissue masses with lucent/hypodense centers on radiographs/CT, and hemorrhagic spaces with fluid-fluid levels and enhancing "honeycomb" septations on MRI and it should be kept in mind as a rare cause of shoulder pain.

\section{Declaration of conflicting interests}

The authors declared no conflicts of interest with respect to the authorship and/or publication of this article.

\section{Funding}

The authors received no financial support for the research and/or authorship of this article.

\section{REFERENCES}

1. Jaffe HL, Lichtenstein L. Solitary unicameral bone cyst: With emphasis on the roentgen picture, the pathologic appearance and the pathogenesis. Arch Surg 1942;44:1004-25.

2. Salm R, Sissons HA. Giant-cell tumours of soft tissues. J Pathol 1972;107:27-39.

3. Baker KS, Gould ES, Patel HB, Hwang SJ. Soft tissue aneurysmal bone cyst: a rare case in a middle aged patient. J Radiol Case Rep 2015;9:26-35.

4. Leithner A, Windhager R, Lang S, Haas OA, Kainberger F, Kotz R. Aneurysmal bone cyst. A population based epidemiologic study and literature review. Clin Orthop Relat Res 1999;363:176-9.

5. Hao Y, Wang L, Yan M, Jin F, Ge S, Dai K. Soft tissue aneurysmal bone cyst in a 10-year-old girl. Oncol Lett 2012;3:545-8.

6. Ellison DA, Sawyer JR, Parham DM, Nicholas R Jr. Softtissue aneurysmal bone cyst: report of a case with $t(5 ; 17)$ (q33;p13). Pediatr Dev Pathol 2007;10:46-9.

7. Panoutsakopoulos G, Pandis N, Kyriazoglou I, Gustafson P, Mertens F, Mandahl N. Recurrent $t(16 ; 17)(q 22 ; p 13)$ in aneurysmal bone cysts. Genes Chromosomes Cancer 1999;26:265-6.

8. Sciot R, Dorfman H, Brys P, Dal Cin P, De Wever I, Fletcher CD, et al. Cytogenetic-morphologic correlations in aneurysmal bone cyst, giant cell tumor of bone and combined lesions. A report from the CHAMP study group. Mod Pathol 2000;13:1206-10.

9. Dal Cin P, Kozakewich HP, Goumnerova L, Mankin HJ, Rosenberg AE, Fletcher JA. Variant translocations involving $16 \mathrm{q} 22$ and $17 \mathrm{p} 13$ in solid variant and extraosseous forms of aneurysmal bone cyst. Genes Chromosomes Cancer 2000;28:233-4.

10. Bonakdarpour A, Levy WM, Aegerter E. Primary and secondary aneurysmal bone cyst: a radiological study of 75 cases. Radiology 1978;126:75-83.

11. Martinez V, Sissons HA. Aneurysmal bone cyst. A review of 123 cases including primary lesions and those secondary to other bone pathology. Cancer 1988;61:2291-304.

12. Robinson D, Halperin N, Agar G, Alk D, Rami K. Shoulder girdle neoplasms mimicking frozen shoulder syndrome. J Shoulder Elbow Surg 2003;12:451-5.

13. Lopez LV, Rodriguez MG, Siegal GP, Wei S. Extraskeletal aneurysmal bone cyst: Report of a case and review of the literature. Pathol Res Pract 2017;213:1445-9.

14. Rodríguez-Peralto JL, López-Barea F, Sánchez-Herrera S, Atienza M. Primary aneurysmal cyst of soft tissues (extraosseous aneurysmal cyst). Am J Surg Pathol 1994;18:632-6.

15. Nielsen GP, Fletcher CD, Smith MA, Rybak L, Rosenberg AE. Soft tissue aneurysmal bone cyst: a clinicopathologic study of five cases. Am J Surg Pathol 2002;26:64-9.

16. Kim ST, Kim HJ, Park SW, Baek CH, Byun HS, Kim YM. Nodular fasciitis in the head and neck: CT and MR imaging findings. AJNR Am J Neuroradiol 2005;26:2617-23.

17. Schaffler G, Raith J, Ranner G, Weybora W, Jeserschek R. Radiographic appearance of an ossifying fibromyxoid tumor of soft parts. Skeletal Radiol 1997;26:615-8.

18. Meana Moris AR, García Gonzalez P, Fuente Martin E, Gonzalez Suarez C, Moro Barrero L. Primary giant cell tumor of soft tissue: fluid-fluid levels at MRI (2010:3b). Eur Radiol 2010;20:1539-43.

19. Ajilogba KA, Kaur H, Duncan R, McFarlane JH, Watt AJ. Extraosseous aneurysmal bone cyst in a 12-year-old girl. Pediatr Radiol 2005;35:1240-2.

20. Lee KH, Joo JK, Kim DY, Lee JS, Choi C, Lee JH. Mesenteric extraskeletal osteosarcoma with telangiectatic features: a case report. BMC Cancer 2007;7:82.

21. Park HY, Yang SK, Sheppard WL, Hegde V, Zoller SD, Nelson SD, et al. Current management of aneurysmal bone cysts. Curr Rev Musculoskelet Med 2016;9:435-44.

22. Biesecker JL, Marcove RC, Huvos AG, Miké V. Aneurysmal bone cysts. A clinicopathologic study of 66 cases. Cancer 1970;26:615-25.

23. Feigenberg SJ, Marcus RB Jr, Zlotecki RA, Scarborough MT, Berrey BH, Enneking WF. Megavoltage radiotherapy for aneurysmal bone cysts. Int J Radiat Oncol Biol Phys 2001;49:1243-7. 